\title{
Central de Turismo Social do SESC/Florianópolis-SC: a inclusão pela via do turismo
}

\section{Central Bureau of Social Tourism SESC / Florianopolis-SC: inclusion through tourism \\ Oficina Central de Turismo Social SESC / Florianópolis-SC: la inclusión a través del turismo}

Juliana Pereira ${ }^{1}$

Luiz Moretto Neto ${ }^{2}$

Ruth Zanini ${ }^{3}$

\section{Resumo}

Este artigo foi desenvolvido na Central de Turismo Social do SESC/Florianópolis, que é uma agência de serviços voltada para o segmento de Turismo Social. A metodologia aplicada consiste em estudo descritivo, com caráter quantitativo, apresentado sobre o método de estudo de caso. Os procedimentos de coleta de dados utilizados foram análise documental, aplicação de questionários e observação participante. Em destaque, verificou-se que a Instituição desenvolve como estratégia, a oferta de uma estrutura adequada para inserir a Base da Pirâmide no segmento turístico, entretanto, esta categoria não utiliza todo o potencial dos serviços ofertados. Com a análise dos dados constatou-se que os resultados obtidos com as ações estratégicas são satisfatórios e desempenham o propósito de inclusão social.

Palavras-chave: base da pirâmide; turismo social; empresa social.

\begin{abstract}
Updating is required to meet new challenges, market trends and changes in consumer behavior. It implies innovative strategies and decision-making in Tourism, including the travel agencies' field. Thus, researches and development plans become fundamental for keeping any touristic enterprise operational and for prolonging its life cycle. This holds truth for regular businesses as well as for Social Tourism endeavors, which aim particularly at the bottom of the pyramid. This work has been developed at Central de Turismo Social(Social Tourism Center) of SESC(Commerce Social Service) in Florianópolis. The Center is a travel agency focused on Social Tourism projects. This article is based on The Fortune at the Bottom of the Pyramid(Prahalad, 2005), Creating a World Without Poverty(Yunus, 2008), Social Tourism(SESC 2009), besides survey of the profile and habits of the Center users. Since Prahalad's and Yunus' concepts served as guide for the analysis, this work's objective
\end{abstract}

\footnotetext{
${ }^{1}$ Pós-graduanda em Gestão de Pessoas nas Organizações - Universidade Federal de Santa Catarina - UFSC. Bacharel em Administração - UFSC. Exerce função de tutora de ensino a distância cursos CAD - UFSC. E-mail: jpjulianapereira@gmail.com.

2 Professor Doutor Associado III da UFSC. Ministra aulas em Programas de Mestrado em Administração e Administração Universitária na UFSC. Exerceu funções de Presidente, Diretor de Planejamento e de Operações do órgão Oficial de Turismo de Santa Catarina. E-mail: moretto@cse.ufsc.br.

${ }^{3}$ Bacharel em Turismo e Hotelaria - UNIVALI. Estudante de Graduação em Serviço Social - UFSC. Estudante em Técnico em Saúde e Segurança do Trabalho - IF/SC. E-mail: ruthzanini_th@yahoo.com.
} 
is to contribute to the practice of Social Tourism and a fair commerce. The methodology consists of a descriptive study with a quantitative character, presented in the form of a case study. The data collection methods used were document analysis, questionnaires and participant observation. It is important to highlight the institution offers an adequate structure as a strategy to insert the bottom of the pyramid into the tourist segment. However, the offered services are not used to their full potential. In summary, the results achieved with the strategic actions are satisfactory and allow to qualify the institution as social inclusive.

Keywords: bottom of the pyramid; social tourism; social business.

\section{Resumen}

Este artículo fue desarrollado en la Oficina Central de Turismo Social SESC / Florianópolis, que es una agencia de servicios dedicada al segmento de turismo social. La metodología consiste en un estudio descriptivo con carácter cuantitativo, que aparecen en el método de estudio de caso. Los procedimientos utilizados para la recolección de datos fueron el análisis de documentos, cuestionarios y observación participante. Destacados, se constató que la institución desarrolla una estrategia, la provisión de una infraestructura adecuada para entrar en la base de la pirámide en el sector turístico, sin embargo, esta categoría no utiliza todo el potencial de los servicios ofrecidos. Con el análisis de datos encontró que los resultados obtenidos con las acciones estratégicas son satisfactorios y el juego con el propósito de la inclusión social.

Palabras clave: base de la pirámide; turismo sociales; emprendimientos sociales.

\section{Introdução}

A atividade turística é um fenômeno interdisciplinar que tem como base a movimentação das pessoas para locais diferentes daquele de sua residência em função de necessidades, desejos profissionais e pessoais.

Assim, o turismo se tornou uma realidade há muito tempo, porém, suas características nem sempre foram tais como se apresentam atualmente. Seu conceito e sua abrangência vêm se modificando ao longo dos anos de acordo com a complexidade da atividade, influências, abrangências e mudanças na economia e tecnologia.

A evolução do setor turístico no Brasil representa uma oportunidade para o desenvolvimento socioeconômico do território e cria uma expectativa sobre a importância da atividade para a melhoria na qualidade de vida da população e a inclusão social nos espaços turísticos.

O Ministério do Turismo - Mtur (2010), possui como objetivo desenvolver o turismo como uma atividade econômica auto-sustentável em geração de empregos e divisas, proporcionando inclusão social. 

sustentável e a inclusão social, pois agrega um conjunto de dimensões favoráveis, proporcionando a ruptura do isolamento.

Nesse contexto de inclusão e melhoria na qualidade de vida da população, surge o Turismo Social, segmento este que amplia as possibilidades de turismo para as camadas populares, criando uma alternativa de democratização do turismo e contribuindo para a inclusão, uma vez que favorece a coesão social.

Para Prahalad e Stuart (2002), o futuro dos negócios está na Base da Pirâmide, ou seja, nas classes menos favorecidas. Criar produtos e serviços acessíveis às camadas populares é uma forte estratégia para a diminuição da pobreza. O Turismo Social visa atender esses consumidores, mas para isso se faz necessário o desenvolvimento de estratégias voltadas para inserir a Base da Pirâmide de forma efetiva no mercado turístico.

O capitalismo adota uma visão estreita da natureza humana, presumindo que as pessoas são seres unidimensionais, interessadas apenas na busca de lucro máximo. Segundo Yunus (2008), para tornar a natureza do capitalismo completa é preciso introduzir outro tipo de organização, que reconheça a natureza multidimensional dos seres humanos.

Para o autor, esse novo tipo de empresa não tem como objetivo apenas o lucro, seria uma empresa totalmente voltada à resolução de problemas sociais. Tal como as outras empresas, ela emprega funcionários, cria bens ou serviços e fornece-os aos clientes a um preço compatível com o seu propósito.

Em suma, uma Empresa Social é projetada e dirigida como um empreendimento, com produtos, serviços, clientes, mercados, despesas e receitas, a diferença é que o princípio da maximização dos lucros é substituído pelo benefício social. Em vez de acumular o maior lucro financeiro possível, para ser desfrutado pelos investidores, a Empresa Social procura alcançar objetivos sociais (YUNUS, 2008).

O Turismo Social enquanto modalidade comercial, isto é, envolvendo negócios turísticos (pacotes, hospedagem, alimentação), já é uma realidade exercida pelos consumidores de baixa renda, ainda que de maneira incipiente. De certa forma, o principal desafio da promoção desse segmento turístico implica no estímulo a organização, ao desenvolvimento e a expansão dessa atividade. 
Com base no cenário exposto e seguindo o referencial teórico da Riqueza na Base da Pirâmide (PRAHALAD, 2005) e da Empresa Social (YUNUS, 2008), este artigo concentra o seu foco na análise dos dados relacionados ao perfil dos usuários dos serviços organizados de turismo ofertados pelo SESC/Florianópolis.

\section{Fundamentação Teórica}

Para embasar o presente estudo foi empreendida análise da abordagem teórica de Prahalad (2005), relativa à riqueza presente na Base da Pirâmide Social e estabelecida interface com a visão de Empresa Social sistematiza por Yunus (2008). A partir desses pressupostos é possível interpretar o objeto de estudo - Central de Turismo Social do SESC/Florianópolis.

\subsection{Base da pirâmide e a atividade de turismo social}

Para Rosenburg e Ribeiro (2008), no sistema capitalista, quanto maior a riqueza das pessoas, maior é o incentivo financeiro para que elas tenham suas necessidades atendidas. Quanto menor a riqueza, menor o incentivo. E é neste quadro, que precisamos encontrar maneiras de fazer com que os aspectos do capitalismo que beneficiam os ricos atendam também aos pobres.

Segundo Teodósio (2009), uma das abordagens mais recentes, dentre uma multiplicidade de conceitos e tendências neste sentido, é a chamada Base da Pirâmide -BoP, a qual pretende orientar as estratégias empresariais em direção aos milhões de consumidores de baixa renda no planeta.

As estratégias voltadas para a Base da Pirâmide vêm ao encontro à criação de produtos e serviços acessíveis às camadas carentes da população para a diminuição da pobreza que devasta vários países do mundo, dentre eles, o Brasil. Essa é a proposta de Prahalad, um dos mais influentes especialistas em estratégia empresarial da atualidade.

Nesta perspectiva Prahalad destaca como fatores essenciais para atuação organizacional voltada ao campo da inovação em mercados centrados na BoP: a relação entre preço e desempenho de produtos e serviços, ou seja, a variável determinante deve estar equilibrada nessa relação dual. $\mathrm{O}$ atendimento a Base da Pirâmide não é sinônimo da adoção de tecnologias obsoletas, aliás, o processo de transposição de soluções tecnológica de países centrais aos periféricos exige adaptações. Outra dimensão trabalhada por Prahalad diz respeito à economicidade e a eficiência ecológica dos processos produtivos para não comprometer o consumo de bens e serviços que possam gerar impactos ambientais irreversíveis. Essa 
perspectiva pressupõe que a inovação deve ser uma dimensão constante nas ações organizacionais voltadas a esse segmento social.

Ainda voltado a Base da Pirâmide o autor reforça a importância da qualificação do capital humano envolvido no processo produtivo e a sua capacitação sendo realizada por meio de mecanismos não convencionais que contribuíam para a relação equilibrada entre preço e desempenho.

Para Torretta (2009), Prahalad não inventou nada, apenas viu que existia uma riqueza na BoP. E a genialidade de sua observação revelou que existe dinheiro na Base da Pirâmide e que colocar essas pessoas dentro da economia gera dinheiro, lucros e faz com que elas tenham a possibilidade do consumo. Esse movimento também gera desenvolvimento econômico, que traz no seu bojo desenvolvimento social, que por fim trará educação, discernimento, cidadania e dignidade.

Em consonância com o atendimento da BoP no consumo de bens e serviços Yunus (2008), tece uma crítica reflexiva a teoria convencional dos negócios e destaca que a mesma está embasada em um pressuposto unidimensional do homem atribuindo ao mesmo o papel de um líder empresarial denominado de empreendedor. $\mathrm{O}$ desafio freqüente na sociedade de mercado é compreender o homem na sua perspectiva multifacetada em que as racionalidades instrumentais e substantiva necessitam estar equilibradas e que o papel das organizações não é exclusivo a geração de lucros e sim a solução de problemas sociais e ambientais (Yunus, 2008).

A contribuição de Yunus adquiri contornos definidos a partir da concepção da empresa social cujo foco é ser um agente de mudanças do meio, um instrumento de inclusão social e de benefício aos atores sociais com as quais interage.

Segundo Prahalad e Stuart (2002), os investimentos na BoP tirariam bilhões de pessoas da miséria e do desespero, evitando a desintegração social, o caos político, o terrorismo e a decadência ambiental que certamente incidirão se o fosso entre países ricos e pobres continuar a crescer.

Contudo, não devemos esquecer que os consumidores não possuem costumes, hábitos e necessidades homogêneas em qualquer das classes social no Brasil, conforme ressalta Torretta (2009).

Em se tratando de classificação de classes sociais e a fim de estabelecer um critério único de classificação para este estudo, optou-se por utilizar o Critério de Classificação Econômica Brasil, conhecido também como Critério Brasil, da Associação Brasileira de Empresas de Pesquisa ABEP (2009), que divide o Brasil em oito categorias: A1, A2, B1, B2, C1, C2, D, E. 
A tabela a seguir demonstra a renda familiar das oito categorias ou classes econômicas, classificadas pela ABEP.

Tabela 01: Informações referentes à renda familiar mensal por classes no Brasil.

\begin{tabular}{|c|c|c|}
\hline \multicolumn{3}{|c|}{ RENDA FAMILIAR POR CLASSES } \\
\hline \multirow{2}{*}{ Classe } & \multicolumn{2}{|c|}{ Renda média familiar (R\$) } \\
\cline { 2 - 3 } & $\mathbf{2 0 0 6}$ & $\mathbf{2 0 0 7}$ \\
\hline $\mathrm{A} 1$ & 10.697 & 14.250 \\
\hline $\mathrm{A} 2$ & 6.556 & 7.557 \\
\hline $\mathrm{B} 1$ & 3.913 & 3.944 \\
\hline $\mathrm{B} 2$ & 2.107 & 2.256 \\
\hline $\mathrm{C} 1$ & 1.288 & 1.318 \\
\hline $\mathrm{C} 2$ & 849 & 861 \\
\hline $\mathrm{D}$ & 549 & 573 \\
\hline E & 318 & 329 \\
\hline
\end{tabular}

Fonte: Adaptado de Associação Brasileira de Empresas de Pesquisa (2009).

Assim, segundo essa classificação, o Brasil tem a seguinte configuração: classe A1 com renda média mensal familiar de R\$ 14.250,00; classe “A2" com renda de R\$ 7.557,00; classe B1 com renda de R\$ 3.944,00; classe "B2" com de renda de $\mathrm{R} \$ 2.256,00$; classe " $\mathrm{C} 1$ " com renda de $\mathrm{R} \$ 1.318,00$; classe “C2" com renda de $\mathrm{R} \$ 861,00$; classe “ $\mathrm{D}$ " com renda de $\mathrm{R} \$ 573,00$ e classe E com renda de R $\$ 329,00$.

Alguns autores consideram que a Base da Pirâmide é composta somente pelas classes D e E. No entanto, Chiara (2008), ressalta que no ano de $2007,46 \%$ dos brasileiros pertencia a classe C, diante de $36 \%$ e $34 \%$ em 2006 e 2005 . Com base nos dados, o estudo em questão considera a BoP composta pelas classes sociais "C", "D" e "E".

Portanto, o desenvolvimento de poder aquisitivo na população brasileira da Base da Pirâmide dentro do sistema capitalista vigente, vem ao encontro a uma das repostas e não a mais importante, para diminuir a pobreza e as constantes enfermidades sociais.

Para Yunus (2008), esse tipo de empresa não tem como objetivo central o lucro, seria uma empresa totalmente voltada à resolução de problemas sociais. Tal como as outras empresas, ela emprega funcionários, cria bens ou serviços e fornece-os aos clientes a um preço compatível com o seu propósito.

Nesta perspectiva, o conceito ou a dimensão de Comércio Justo apresenta-se como uma possibilidade concreta para a redução das assimetrias tão presentes nas relações sociais de produção entre os chamados países centrais e periféricos. 
No âmbito macroeconômico as Nações Unidas tem empreendido ações sistemáticas através da Organização Mundial do Comércio e de outras instituições para mitigar as assimetrias entre o Norte e o Sul.

Os objetivos do Milênio definidos em Assembléia Geral das Nações Unidas no ano de 2000 estabelecidas para até o ano de 2015 contemplam ações e esforços públicos e privados para promoção da inclusão social de segmentos expressivos da humanidade que estão alijados do mercado.

Reduzir as assimetrias e promover a inclusão social requer ações e esforços continuados dos agentes públicos, privados e do terceiro setor para possibilitar o acesso ao consumo de bens e serviços, de segmentos até então desconsiderados.

E é dentro deste quadro, que encontramos o SESC, como instituição de caráter público e privado, que tem como principal objetivo atender às necessidades sociais emergentes por meio de um caráter educativo, promovendo o desenvolvimento cultural, o bem-estar social e a qualidade de vida dos trabalhadores do comércio e serviços e de seus dependentes, assim como da comunidade em geral, numa ação de transformação e progresso social, nos grandes centros urbanos (SESC, 2009).

A entidade é pioneira em diversas modalidades de assistência as pessoas que se encontram na Base da Pirâmide, inclusive no desenvolvimento do Turismo Social no Brasil, estimulando este segmento ao longo de toda a sua história.

O SESC segue o conceito do Bureau Internacional Tourisme Social - BITS para definir as diretrizes para seu programa de Turismo Social. O BITS menciona que Turismo Social é "conjunto de relações e fenômenos resultantes da participação no turismo das camadas sociais menos favorecidas, participação esta que se torna possível ou facilitada por medidas de caráter social bem definidas, mas que implicam um predomínio da idéia de serviço e não de lucro.”

Seguindo o conceito do BITS, o SESC se enquadra na proposta de Prahalad, que menciona que os investimentos na Base da Pirâmide, ou seja, nas classes menos favorecidas tirariam bilhões de pessoas da miséria, evitando a desintegração social, o caos político e decadência ambiental.

O Turismo Social na instituição trabalha é direcionado aos segmentos situados na base da pirâmide, por meio da redução de custos nas excursões e demais atividades de Turismo Social, promovendo também, ações no campo educacional, cultural, religioso, de saúde e 
rural. Priorizando a vertente educativa, que faz parte do esforço para a promoção de oportunidades de lazer que proporcionem integração interpessoal, enriquecimento cultural e desenvolvimento integral da saúde (SESC, 2009).

De acordo com o documento institucional do SESC (2003), o programa de Turismo Social do SESC deve atender, prioritariamente, aos trabalhadores das empresas de comércio de bens e serviços e seus dependentes, de todas as faixas etárias. Entretanto, seus bens, serviços e seus produtos turísticos podem ser disponibilizados ao público não-comerciário, com a adoção de preços diferenciados, desde que não venha prejudicar a demanda interna.

Sendo assim, o programa de Turismo Social é extensivo aos comerciários e seus dependentes, conveniados, empresários e usuários, com adoção de tarifa diferenciada conforme a classificação na qual a pessoa se enquadra. As tarifas dos passeios e excursões apresentam menor valor para os comerciários e dependentes, incluindo as pessoas maiores de 60 anos.

É possível constatar que o SESC, trabalha de acordo como o pressuposto de Yunus, sendo uma empresa social que não pratica o subsídio, mas busca um ponto de equilíbrio nas atividades que desenvolve.

Também, sua função não se resumiu apenas em um serviço isolado de realização de excursões interestaduais, mas pressupõe a integração no sistema SESC de todo o equipamento de lazer para aproveitamento do tempo livre dos seus associados. Apresentando-se em três modalidades: turismo emissivo, turismo receptivo e hospedagem.

Entretanto, como já mencionado anteriormente e em virtude da heterogeneidade do comportamento de consumidores, inclusive das classes sociais "C", " $D$ " e "E" e das constantes mudanças que vem ocorrendo na atividade turística, tem sido constatado necessidade de atualizar cada vez mais as novas exigências e tendências do mercado atual, para que o SESC consiga se manter na atividade turísticas ao mesmo tempo em que não se desvirtue do seu objetivo social e conflite com os interesses patronais.

Amparados nos pressupostos teóricos da Riqueza na Base da Pirâmide (PRAHALAD, 2005) e da Empresa Social (YUNUS, 2008), este artigo concentra o seu foco na análise dos dados relacionados ao perfil dos usuários dos serviços organizados de turismo ofertados pelo SESC/Florianópolis no período de 14 a 21 de maio de 2010. 


\section{Metodologia}

Seguindo os conceitos de Gil (2002), uma pesquisa, em função dos seus objetivos, pode ser classificada como: exploratória, descritiva e explicativa. Do ponto de vista dos objetivos a que se propõe, o presente artigo contempla aspectos de pesquisa descritiva, pois busca o entendimento do fenômeno como um todo.

Conforme Godoy (1995), a pesquisa se caracteriza como um esforço para a descoberta de novas informações ou relações e para a verificação e ampliação do conhecimento existente, o caminho seguido nesta busca pode possuir contornos diferentes, podendo assumir características quantitativas ou qualitativas.

É possível definir que o estudo em questão é predominantemente de caráter quantitativo, pois se utilizou métodos estatísticos na interpretação dos dados.

Adotou-se uma abordagem de estudo de caso, sendo que a escolha por esse tipo de pesquisa se deu em função da necessidade de conhecer de forma mais detalhada o programa de Turismo Social do SESC/Florianópolis. A pesquisa documental foi utilizada como forma complementar, mas o estudo de caso prevalece como a abordagem principal.

Segundo Lakatos e Marconi (1991), toda pesquisa implica o levantamento de dados de variadas fontes, quaisquer que sejam os métodos ou técnicas empregadas. As autoras ainda mencionam que o levantamento de dados é o primeiro passo de qualquer pesquisa, sendo realizado de duas maneiras: dados primários e secundários. Foram pesquisados documentos da Instituição e aplicados questionários com clientes do SESC/Florianópolis.

Os participantes do estudo, ou seja, as pessoas que contribuíram com as informações relevantes para que o trabalho fosse realizado, integram o Departamento Regional do SESC/Santa Catarina, os representantes e colaboradores da Unidade SESC/Florianópolis, bem como, o público que freqüenta a Instituição.

Tendo como base que a média de clientes por ano no SESC/Florianópolis, gira em torno de mais de 29.000 pessoas por ano, a presente pesquisa constitui-se na aplicação de 303 questionários com 1 pergunta aberta e 25 perguntas fechadas, de caráter qualitativo, aplicadas entre os dias 14 a 21 de maio de 2010, com pessoas maiores de 18 anos, com o cadastro atualizado na Instituição, que utilizam algum tipo de serviço dentro Unidade do SESC/Florianópolis. 
As questões foram dividias de modo a contemplar o perfil dos usuários, o comportamento de compra e vislumbrar a situação e imagem da Central de Turismo Social Emissivo, frente aos seus clientes.

Ressalta-se, no entanto, que para a quantidade de clientes anuais da Instituição, se faz necessário a aplicação de 397 questionários, através do método estatístico de amostragem, simples e aleatório e com margem de erro de 5\%. Contudo, devido aos trâmites internos para a autorização e aplicação dos questionários, bem como, à disponibilidade de tempo, condições e necessidade de dar continuidade a outras etapas do presente projeto de ação, optou-se por delimitar a quantidade de questionários.

Desta forma, os dados obtidos foram tabulados e transformados em gráficos comparativos, e posteriormente analisados de forma a contemplar o perfil dos usuários dentro do SESC/Florianópolis, bem como, o comportamento de compra e vislumbrar a situação e imagem da Central de Turismo Social Emissivo, frente a estes clientes.

\section{Resultados da Pesquisa}

Tendo como base que a média de clientes atendidos por ano no SESC/Florianópolis, gira em torno de 29.000 pessoas, a pesquisa constitui-se na aplicação de 303 questionários com perguntas fechadas, de caráter qualitativo, aplicadas entre os dias 14 a 21 de maio de 2010, com pessoas maiores de 18 anos, com o cadastro atualizado na Instituição e que utilizam algum tipo de serviço dentro Unidade do SESC/Florianópolis. Os dados obtidos foram tabulados e transformados em gráficos comparativos, e posteriormente analisados de forma a contemplar o perfil do usuário na Unidade.

O levantamento de dados no SESC/Florianópolis possibilitou identificar os aspectos referentes ao perfil sócio-econômico, o hábito de uso dos serviços e atividades dentro da unidade do SESC/Florianópolis, o conhecimento dos entrevistados em referência a Central de Turismo Social e seus serviços, bem como, o perfil de compra e comportamento dentro da atividade turística.

Desta forma, constatou-se de modo particular, que o grande percentual dos entrevistados, foi da categoria comerciário, ou seja, trabalhador do comércio, do sexo feminino, com idade entre 32 a 40 anos, casado, com ensino médio completo, renda mensal individual de 1 a 3 salários mínimos e familiar, de 3 a 5 salários mínimos, residente na grande Florianópolis, usuário da 
unidade a mais de 5 anos e que utiliza primordialmente os serviços de saúde, seguido pelos serviços de lazer e educação.

Portanto, é possível constatar que o público alvo do SESC é formado por sujeitos que integram a Base da Pirâmide, sendo esta composta das classes “C”, "D” e "E” (Prahalad, 2005).

Todavia, a partir dos resultados pertinentes à Central de Turismo Social do SESC/Florianópolis, verificou-se que 36,63\% conhece a Central de Turismo Social, seguido de $44,22 \%$ das pessoas que já ouviram falar do setor, por meio dos materiais promocionais distribuídos dentro da Instituição, pela localização, por terem realizado alguma programação pelo setor ou pelos cartazes distribuídos dentro da Unidade. Os dados permitiram constatar ainda, que $84,16 \%$ dos entrevistados nunca viajaram pelo setor, principalmente por não possuírem tempo disponível ou por não conhecerem a totalidade dos serviços do setor. Constatou-se também, que os entrevistados gostariam de receber as informações dos serviços por e-mail e que não possuem preferência em realizar alguma programação de viagem especifica pelo SESC.

Cabe, portanto, reflexão de ordem institucional relativa ao processo de comunicação dos serviços distribuídos para os seus públicos.

É necessário destacar que a Central de Turismo Social é vista como um setor de serviço, como outros na Instituição. Entretanto, por operar com pacotes e roteiros turísticos organizados para grupos de excursões, buscou-se o registro no Ministério do Turismo como agência de viagens, a fim de regularizar os serviços a serem oferecidos dentro das normas e leis vigentes.

Neste contexto, o SESC apresenta forte aderência à percepção de Empresa Social (Yunus, 2008).

Porém, apesar da Central de Turismo Social possuir este registro, como agência de viagens, que é um tipo de atividade que objetiva o lucro e procura um posicionamento marcante no mercado, o setor de turismo social emissivo do SESC/Florianópolis, não procura se destacar dentro do cenário de agenciamento de viagens, por algumas razões, dentre as quais, apresentase: não transformar o setor em um empreendimento comercial e não apresentá-lo como agência de viagens concorrente no mercado.

Esta ação institucional, entretanto, é convergente ao atendimento de segmento situado na base da Pirâmide. 
Já, com relação ao hábito de viajar, foi declarado por 75,90\% dos entrevistados, que estes, realizam pelo menos uma a duas viagens turísticas por ano e que preferem organizar as suas próprias viagens em virtude do custo em relação ao benefício e pela maior flexibilidade para realizar seus próprios roteiros. Além disso, os respondentes declaram, com porcentagem significativa, 54,13\%, que preferem se hospedar em hotéis, e 34,32\% em casas de amigos e familiares, utilizar no seu deslocamento para o destino um automóvel e/ou ônibus de linha, bem como, viajar com a família ou com o(a) cônjuge, neste caso, aconselha-se ao setor buscar alternativas para atrair este público, lançando novos produtos e incrementado os atuais para atender os vários perfis de clientes.

A pesquisa demonstrou também, que os indivíduos escolhem o período de férias para viajar ou quando surge uma oportunidade apropriada, aliando o tempo disponível, o custo verso benefício e a disponibilidade de todos os membros da família. Constatou-se ainda, que os entrevistados levam em média, de um mês a dois meses para organizar e programar uma viagem turística.

As programações de viagens e excursões, de acordo com informações da técnica responsável pelo setor dentro da Unidade em Florianópolis, Luana Emmendoerfer, totalizam uma média de $75 \%$ de todos os roteiros do Estado, seguido por Joinville e Blumenau. Verifica-se, assim, a importância da existência do setor para o Estado de Santa Catarina e para a difusão do Turismo Social Emissivo em Florianópolis.

Analisando o produto ofertado pelo SESC-Florianópolis, observa-se que $41 \%$ das programações são de 01 dia, 44,50\% dos roteiros são de 02 a 04 dias, 10,50\% dos roteiros são de 05 a 10 dias e 4,5\% dos roteiros, de mais de 10 dias. Em relação aos períodos do ano em que são realizados os roteiros, em média, 43,50\% na baixa estação e 56,50\% na alta estação3. Os dias em que são realizadas estas viagens e excursões, em média, com $64,50 \%$ ocorrem nos finais de semana, e 35,50\% nos dias de semana, considerando que quando a excursão englobar dias no meio e final de semana, por exemplo, de quinta-feira a domingo, são consideradas programações de final de semana.

Com relação à demanda efetiva, faz-se necessário considerar a tabela a seguir, que nos apresenta o percentual das categorias que utilizaram o serviço de Turismo Social na Unidade Operacional do SESC-Florianópolis, nos últimos três anos: 
Tabela 02: Porcentagem de inscrições da Central de Turismo Social do SESC/Florianópolis nos últimos 3 anos por categoria.

\begin{tabular}{|c|c|c|c|}
\hline Ano & Comerciário & $\begin{array}{l}\text { Dependentes de } \\
\text { Comerciários }\end{array}$ & $\begin{array}{c}\text { Usuários } \\
\text { (comunidade, empresários e dependentes, } \\
\text { conveniados e dependentes e pessoas } \\
\text { acima de } 60 \text { anos) }\end{array}$ \\
\hline 2007 & $7,17 \%$ & $40,44 \%$ & $52,39 \%$ \\
\hline 2008 & $12,29 \%$ & $34,71 \%$ & $53 \%$ \\
\hline 2009 & $12,71 \%$ & $34,51 \%$ & $52,78 \%$ \\
\hline
\end{tabular}

SESC/Florianópolis, 2010.

Na tabela, também se observa que o público da categoria usuário permaneceu em uma mesma média e os dependentes de comerciários diminuíram no mesmo período, compensando o crescimento da categoria comerciário. Se somar os crescimentos anuais de todas as categorias e diminuí-los dos indicadores negativos de crescimento, concluí-se que, nos anos de 2007/2008 e 2008/2009, os índices permaneceram iguais ou não houve aumento na demanda atendida. Neste sentido, seria interessante potencializar a divulgação do setor para estas categorias, contribuindo para aumentar os índices de atendimento do público-alvo, favorecendo a promoção e crescimento do turismo social.

Com relação à política de preços dos serviços oferecidos pela Central de Turismo Social Emissivo do SESC-Florianópolis, o custo da programação repassada aos clientes almeja a busca de valores reduzidos, procurando-se o equilíbrio entre a receita e despesa do roteiro, bem como, repassá-los aos clientes, de acordo com a sua categoria dentro da Instituição.

Para as pessoas com mais de 60 anos, o SESC concede a possibilidade de pagamento no mesmo valor da categoria comerciário. Há ainda uma diferenciação de preços para crianças na faixa etária de 0 a 12 anos. As formas de pagamento das programações podem ser realizadas à vista, através de cartão de crédito (bandeira Visa e Mastercard), em 10 vezes sem juros ou boleto bancário, até a data da viagem.

Constata-se por meio dos aspectos levantados, a respeito da política de preços da Unidade, que o setor utiliza as normas estabelecidas pela Instituição, tendo como princípios a não lucratividade e roteiros mais acessíveis. No entanto, o preço dos roteiros pode não ser considerado atrativo para o público alvo, por exemplo, num pacote para Festa Junina no Hotel 
Fazenda em Gaspar, 3 dias e 2 noites com pensão completa, o valor por comerciário é de R\$ 370,00, e para crianças de 3 a 12 anos, R\$ 190,00. Considerando uma família com dois adultos e uma criança até 12 anos, o valor total investido para a programação é de R\$930,00, montante que pode ser percebido como elevado, mesmo com as facilidades de pagamento, para uma família com renda total de até 3 salários mínimos. Observa-se também que os valores apresentados para este roteiro estão bem abaixo em comparação com o mercado, visto que a mesma programação pode ser adquirida no valor de $\mathrm{R} \$ 1.280,00$ através do contato direto com o hotel.

Entre os aspectos ligados aos roteiros, os três segmentos turísticos de maior preferência dos entrevistados foram os roteiros ligados a sol e praia, rural e aventura. Sendo que destes, apontaram como atividades idealizadas, fazer visitas e passeios para conhecer os pontos turísticos, realizar atividades culturais e freqüentar praias ou tomar sol.

Com relação à disponibilidade financeira para investir numa viagem turística, de acordo com os declarantes, o item, até 1 salário mínimo ou até 2 salários mínimos, foram os mais citados, sendo que o pagamento à vista foi a forma de pagamento mais pontuada.

Dentre as palavras que expressam o significado da atividade turística para os entrevistados, os aspectos ligados ao bem-estar social individual, foram os mais significativos, que são o descanso, novas experiências e entretenimento. Neste sentido, observa-se a necessidade da valorização do cliente para buscar a sua satisfação e fidelização.

Ressalta-se também, que durante as diversas fases e períodos de aplicação dos questionários, foi possível observar a inegável importância da atividade turística para o desenvolvimento social do indivíduo e seu bem-estar. No entanto, confirmou-se, também, que se faz necessário, para atingir um número maior de comerciários, diferenciar as formas de promoção existentes dentro da Instituição, em especial para os serviços propostos pela Central de Turismo, bem como, desenvolver novos roteiros que atendam as expectativas dos clientes e se adéqüem as suas e renda disponível.

\section{Considerações Finais}

O presente estudo foi realizado na Central de Turismo Social do SESC/Florianópolis durante o primeiro semestre de 2010 para avaliar os processos de planejamento, organização e 
distribuição de produtos de natureza turísticos, através daquela unidade funcional, aos comerciários da Grande Florianópolis.

A interpretação do fenômeno social analisado foi sistematizada a partir de pressupostos teóricos definidos por Prahalad (2005) e Yunus (2008), respectivamente nas obras "A riqueza na base da pirâmide" e "Um mundo sem pobreza".

A premissa dominante na obra de Prahalad, diz respeito ao potencial de consumo não aproveitado em relação aos consumidores de baixa renda e para tanto o autor destaca que atuar na Base da Pirâmide não é sinônimo de oferta de bens e serviços a partir de tecnologias ultrapassados nem a ênfase predominante no enfoque da economicidade a qualquer custo.

Sua abordagem, portanto, contempla a dimensão da inclusão social pela via do consumo, numa perspectiva de cidadania social, que possibilite a todos a dignidade e a isonomia nas relações de produção e consumo.

Os pressupostos teóricos trabalhados por Prahalad (2005) encontram total ressonância nas ações institucionais do SESC por meio da operação do Turismo Social, seja possibilitando o lazer aos comerciários e seus dependentes.

De outra parte, a proposta de Yunus (2008) materializa, pela via do mercado, o desenvolvimento social sustentável, na medida em que estabelece relações de produção com o homem numa perspectiva multidimensional. Ou seja, interpreta-o como ser dotado, de racionalidade instrumental e substantiva e atribui às organizações uma dupla e simultânea função que é a geração da riqueza aliada à solução de problemas sociais e ambientais derivados do processo produtivo.

Sua contribuição central reside na definição na Empresa Social entendida como uma organização voltada à resolução de problemas sociais, geração de emprego, renda, distribuição de bens e serviços aos usuários a partir da perspectiva de Comércio Justo. Entendido como relações de troca marcadas pela mitigação de assimetrias nas relações de produção e consumo.

A busca de ações voltadas ao atendimento a Base da Pirâmide e a cooperação através de Empresas Sociais, convergem com os objetivos do Milênio estabelecidos pelas Nações Unidas até 2015 e tem como foco a inclusão social de segmentos expressivos da humanidade que se encontram aleijados do mercado. 
A inclusão social pela via do mercado e a redução das assimetrias presentes nas relações de consumo são desafios de grande magnitude que se apresentam a todos os agentes públicos, privados e as sociedades em geral, no âmbito mundial.

Nesta perspectiva o SESC, por meio do seu Programa de Turismo Social empreende ações para a oferta de programas de lazer aos segmentos situados na Base da Pirâmide operando na perspectiva de uma Empresa Social, sem as ações de subsídios e em busca de equilíbrio econômico, financeiro e sustentável das atividades que empreende.

\section{Referências}

ABEP - ASSOCIAÇÃO BRASILEIRA DE EMPRESAS DE PESQUISA. Apresenta informações gerais sobre Critério de Classificação Econômica Brasil. Disponível em: $<$ http://www.abep.org/codigosguias/CCEB2008-Base2006e2007.pdf >. Acesso em 10 set 2009.

CHIARA, Márcia de. Com 86 milhões de pessoas, classe $C$ já é maioria da população brasileira. O Estado de São Paulo, março de 2008. Disponível em: $<$ http://blogdofavre.ig.com.br/tag/ipsos/>. Acesso em 16 set 2009.

GIL, Antonio Carlos. Como elaborar projetos de pesquisa. 4. Ed. São Paulo: Atlas. 2002.

GODOY, Arilda Schmidt. Pesquisa qualitativa: tipos fundamentais. Revista de Administração de Empresas. São Paulo, v.35, n.3, 1995. p.20-29. Mai/Jun.

LAKATOS, Eva Maria; MARCONI, Marina de Andrade. Metodologia do trabalho científico. São Paulo: Atlas. 1991.

PRAHALAD, C. K. A riqueza da base da pirâmide: como erradicar a pobreza com o lucro. Porto Alegre: Bookman. 2005.

. STUART L.H,. O pote de ouro a base da pirâmide. Revista HSM Management, maio - junho. 2002.

ROSENBURG, Cynthia. RIBEIRO, Aline. Em busca do capitalismo criativo. Revista Época Negócios. 2008.

RUA, Maria das Graças. Turismo e políticas públicas de inclusão. In. Turismo social: diálogos do turismo, uma viagem de inclusão. Ministério do Turismo, Instituto Brasileiro de Administração Municipal - Rio de Janeiro: IBAM. 2006.

SANTOS, Patrícia Carmo dos (Org.). Modelo da atividade turismo social: módulo de turismo emissivo. Rio de Janeiro: SESC. 2007.

SESC - SERVIÇO SOCIAL DO COMÉRCIO. Apresenta informações gerais sobre o programa de Turismo Social do SESC, unidade Santa Catarina. Disponível em: $<$ http://www.sescsc.com.br/turismo/index.php>. Acesso em: 2 set 2009

Turismo Social: modelo da atividade. Divisão de Planejamento e Desenvolvimento - DPD, Gerência de Estudos e Pesquisas - GEP. SESC, Departamento Nacional. 2003. 
TEODÓSIO, Armindo dos Santos de Sousa. O longo e tortuoso caminho em direção à base da pirâmide. Disponível em: <http://www.rae.com.br/redirect.cfm?ID=4686>. Acesso em 15 set 2009.

TORETTA, André. Mergulho na base da pirâmide: uma nova oportunidade para a sua empresa. São Paulo: Saraiva. 2009.

YUNUS, Muhammad. Criando um negócio social: como iniciativas economicamente viáveis podem solucionar os grandes problemas da sociedade. Rio de Janeiro: Ed. Elsevier. 2010.

Ed. Ática. 2008.

Um mundo sem pobreza: a empresa social e o futuro do capitalismo. São Paulo:

Recebido em: 25/01/2011

Aprovado em: 05/05/2011 